\title{
Millennial minimum temperature variations in the Qilian Mountains, China: evidence from tree rings
}

\author{
Y. Zhang ${ }^{1}$, X. M. Shao ${ }^{1}$, Z.-Y. Yin ${ }^{1,2}$, and Y. Wang ${ }^{1}$ \\ ${ }^{1}$ Key Laboratory of Land Surface Pattern and Simulation, Institute of Geographic Sciences and Natural Resources Research, \\ Chinese Academy of Sciences, Beijing 100101, China \\ ${ }^{2}$ Department of Environmental and Ocean Sciences, University of San Diego, San Diego, CA 92110, USA
}

Correspondence to: X. M. Shao (shaoxm@igsnrr.ac.cn)

Received: 14 December 2013 - Published in Clim. Past Discuss.: 21 January 2014

Revised: 15 September 2014 - Accepted: 16 September 2014 - Published: 24 September 2014

\begin{abstract}
A 1343-year tree-ring chronology was developed from Qilian junipers in the central Qilian Mountains of the northeastern Tibetan Plateau (TP), China. The climatic implications of this chronology were investigated using simple correlation, partial correlation and response function analyses. The chronology was significantly positively correlated with temperature variables prior to and during the growing season, especially with monthly minimum temperature. Minimum temperature anomalies from January to August since AD 670 were then reconstructed based on the treering chronology. The reconstruction explained $58 \%$ of the variance in the instrumental temperature records during the calibration period (1960-2012) and captured the variation patterns in minimum temperature at the annual to centennial timescales over the past millennium. The most recent 50 years were the warmest period, while 1690-1880 was the coldest period since AD 670. Comparisons with other temperature series from neighbouring regions and for the Northern Hemisphere as a whole supported the validity of our reconstruction and suggested that it provided a good regional representation of temperature change in the northeastern Tibetan Plateau. The results of wavelet analysis showed the occurrence of significant quasi-periodic patterns at a number of recurring periods (2-4, 40-50, and 90-170 years), which were consistent with those associated with El NiñoSouthern Oscillation (ENSO), Pacific Decadal Oscillation (PDO) and solar activity. The comparison between the reconstructed temperature and the index of tropical volcanic radiative forcing indicated that some cold events recorded by tree rings may be due to the impact of tropical volcanic eruptions.
\end{abstract}

\section{Introduction}

Understanding temperature variations over the past 1000 years is imperative for evaluating the current global warming and forecasting future temperature changes. Numerous temperature reconstructions based on multiple proxies make it possible to understand the temperature changes during the past millennium (Esper et al., 2012; Jones et al., 1998; Mann et al., 1999; Crowley, 2000; Moberg et al., 2005; D’Arrigo et al., 2006). However, due to the uneven distribution of sample locations, knowledge of temperature variations during the past thousand years remains poor for some areas of the world, such as the Tibetan Plateau (TP).

The TP is well known for its profound influences on both regional and global climate through thermal and dynamical forcing (Ding, 1992; Manabe and Broccoli, 1990; Webster et al., 1998; Zhou et al., 2009). Since the mid-1950s, most of the plateau has experienced a dramatic warming of the climate (Liu and Chen, 2000), which has caused significant changes in the environmental conditions and ecosystems of this area (Yao et al., 2004, 2012; Cyranoski, 2005; Cheng and $\mathrm{Wu}, 2007$; $\mathrm{Xu}$ and Liu, 2007). High-resolution millennium-long records of past temperature variation are urgently needed to understand recent warming trends in the TP better. Tree rings are natural records with annual resolution that provide proxy data for palaeo-environmental studies and reconstructions of various climatic events (Jones et al., 2009). During recent decades, many multiple-centurylong temperature reconstructions have been established for areas within the TP, such as the Qilian Mountains (Tian et al., 2009), the Anemaqin Mountains (Gou et al., 2007a, b), 
the Hengduan Mountains (Fan et al., 2008a, 2009, 2010; Li et al., 2011a), the Nyainqentanglha Mountains (Zhu et al., 2011a), the Tanggula Mountains (Zhu et al., 2011b; Liang et al., 2008), the Sygera Mountains (Liang et al., 2009), and the Himalaya Mountains (Yang et al., 2009a, 2010; Cook et al., 2003; Hughes, 2001; Yadav et al., 2004). However, few millennial-scale temperature series are available. Using the ring widths and stable carbon isotope ratios $\left(\delta^{13} \mathrm{C}\right)$ of Qilian juniper from the upper treeline, Liu et al. (2007) reconstructed the December-April temperature in the Qilian Mountains with a 3-year resolution over the past 1000 years. Zhu et al. (2008), using ring width data from Qilian juniper at the upper treeline, reconstructed mean September-to-April temperatures for the Wulan area, Qinghai Province, since AD 1000. The two reconstructions showed the occurrences of generally low temperatures during AD 1600-1800 and the abrupt warming toward the end of past millennia. However, there were some discrepancies between these series before AD 1500, and the long-term trends were even reversed in the period of AD 1060-1200. Yadav et al. (2011) developed a May-August mean temperature reconstruction extending back to AD 940 derived from tree-ring width data in the western Himalaya, and the centennial-scale variations in the reconstruction revealed the warm periods encompassing the 11-15th centuries, which were different from those in the two reconstructions mentioned above. In addition, by combining samples of archaeological wood and living trees in the eastern Qaidam Basin, Qinghai Province, Liu et al. (2009), reconstructed the annual mean temperature in a large region of the mid-eastern Tibetan Plateau over the past 2485 years. However, the small sample size led to substantial uncertainties for the period of approximately AD 700-900 (Liu et al., 2009). Additionally, it was controversial whether the archaeological samples used in the research were temperature sensitive or moisture sensitive (Shao et al, 2010). The temperature variability in the TP during the past 1500 years, especially before AD 1050, remains poorly understood and substantially uncertain (Ge et al., 2010). Whether temperatures were higher in the earlier periods than today or whether the current warming is unprecedented in the context of the past millennium is still unclear in this area.

Previous studies have indicated that tree-ring samples obtained from low-temperature sites, such as mid-latitude upper treelines and high-latitude regions, tend best to reflect past temperature variations (Fritts, 1976; Körner and Paulsen, 2004; Di Filippo et al., 2007; Sazler et al., 2009). To address the need to expand spatial coverage of millennial length proxies of past temperatures, we collected tree-ring samples from the upper treeline in the Qilian Mountains in the northeastern TP, and developed a new ring-width chronology to investigate the temperature variability in the past. The objectives of this study are (1) to develop a new tree-ring chronology for the timberline forests of the Qilian Mountains in the northeastern TP, (2) to evaluate the validity of this millennial-scale reconstruction, and (3) to reveal the char- acteristics of past temperature changes using the tree-ring chronology. This reconstruction should improve our understanding of temperature variability in the northeastern TP for the past millennium.

\section{Data and methods}

\subsection{Study area}

The study area is located in the Qilian Mountains National Nature Reserve, which is located along the northeastern boundary of the TP, bordering the Inner Mongolia Plateau to the north and the Loess Plateau to the east, with elevations between 2000 and $5000 \mathrm{~m}$ above sea level (hereafter a.s.1.). The climate of the region varies with elevation, forming distinct zones of different vegetation (Chen, 1990). The lower portion of the mountains (2000-2600 m) has a semiarid steppe climate, with annual mean temperatures ranging from 2 to $5^{\circ}$, and annual precipitation of approximately 235 to $330 \mathrm{~mm}$; the upper portion of the mountains (2600$3200 \mathrm{~m}$ ) has a sub-humid forest and steppe climate, with annual mean temperatures ranging from -0.7 to $2^{\circ}$, and annual precipitation of approximately 400 to $500 \mathrm{~mm}$; the subalpine and alpine zones (3200 $\mathrm{m}$ and higher) have a cold and humid climate, with annual mean temperatures of approximately -1.5 to $-0.7^{\circ}$, and annual precipitation of approximately $500 \mathrm{~mm}$ (Chen, 1990). The dominant tree species in the study area are Qilian juniper (Sabina przewalskii Kom.) and Qinghai spruce (Picea crassifolia Kom.) (Yang et al., 2008).

\subsection{Tree-ring data}

The tree-ring samples were collected on the northern slope of the central Qilian Mountains (Fig. 1). Based on repeated field observations, we found that Qilian junipers grew between approximately $2700 \mathrm{~m}$ and $3600 \mathrm{~m}$ a.s.1 in this area. Because most of the trees in the upper treeline are located around $3400 \mathrm{~m}$ a.s.l., four sampling sites were selected with elevations above $3300 \mathrm{~m}$ (Table 1). Standard $5 \mathrm{~mm}$ increment cores were collected from living and relict trees along the local upper treeline and taken to the laboratory for processing. The samples were prepared using standard dendrochronological techniques (Stokes and Smiley, 1968). After measuring each ring to the nearest $0.01 \mathrm{~mm}$, we statistically verified the cross-dating accuracy using the COFECHA program (Holmes, 1983). This program firstly removes the lowfrequency variations from the raw data of ring width by fitting a cubic smooth spline, and then provides the correlation test for succeeding 50-year segments with 25-year overlapping periods (Grissino-Mayer, 2001). Because the four sites were located in close geographic proximity (the longest distance is $6 \mathrm{~km}$, between sites HY0 and HY6), and the mean correlation of all cores in COFECHA was 0.6, all of the raw measurements were merged together to develop a single 


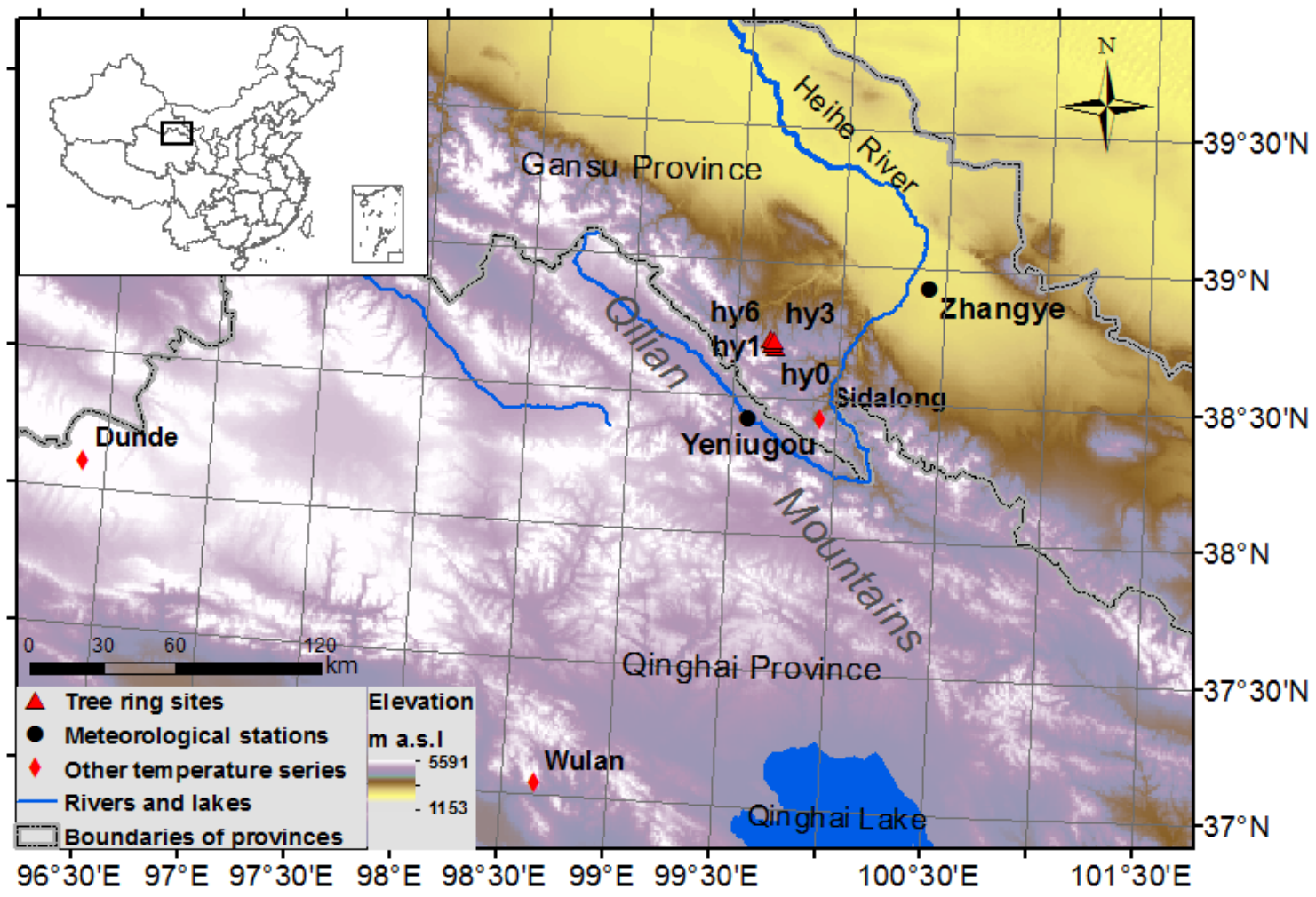

Figure 1. Locations of tree-ring sampling sites, meteorological stations, and other temperature-related series in the Qilian Mountains (Sidalong: Liu et al., 2007; Wulan: Zhu et al., 2008; Dunde: Thompson et al., 2003).

standard chronology (hereafter HY). Two criteria were used to exclude certain series in order to ensure a high signal-tonoise level and obtain the strong temperature signal from the tree-ring series. First, those series that exhibited low correlations with the master series $(r<0.4)$ were excluded from being used in the chronology. Second, series from trees growing in rocks or crevices with mean sensitivity values greater than 0.45 were also excluded. The reason for this is because mean sensitivity is a measure of the relative difference in ring width between adjacent rings, and precipitationsensitive ring width samples tend to have high variability between adjacent rings (Fritts, 1976). For our samples, the mean sensitivity values of most sample series are in the range from 0.15 to 0.45 , while those excluded tree-ring series with higher mean sensitivity values also have more absent rings. After applying these criteria, 152 cores from 82 trees (out of 250 cores and 118 trees, Table 1) were selected to construct the chronology using the ARSTAN program (Cook, 1985), which has the potential to be temperature sensitive.

The negative exponential curve and linear line with a negative slope were used to fit age-related growth trends from the individual tree-ring series for cores that were close to the piths (93 cores). For the cores that were not close to the piths (47 cores) and thus had no growth trend, we simply divided the width values by the respective means to get the index values, equivalent to fitting these cores using the hor- izontal lines through the means. For the cores that reached the piths, the Hugershoff growth curve (4 cores) or a general negative exponential curve (8 cores) was used to fit the growth trends (Cook and Kairiukstis, 1990; Fritts, 1976; Warren, 1980). The final ring-width chronology was obtained by calculating the ratios of the ring-width measurements over the fitted values for each year, producing dimensionless indices with a mean of 1.0. Signal strength of the standard chronology was assessed by the mean inter-series correlation $\left(R_{\text {bar }}\right)$ and the associated expressed population signal (EPS) (Wigley, 1984). EPS is a function of $R_{\mathrm{bar}}$ and the sample size, and estimates the variance fraction of an infinite, hypothetical population expressed by the chronology. Both $R_{\mathrm{bar}}$ and EPS were calculated for 30-year moving windows with 15 -year overlaps along the chronology. To reduce the possible influence of the variable sample size, the variance of the chronology was stabilised using the method described by Osborn et al. (1997). The subsample signal strength (SSS) with a threshold value of 0.85 was used to assess the adequacy of the replications in the early years of the chronology (Wigley, 1984). The SSS estimates the agreement between an average series made from a few samples with one made from an optimum or larger number of series. 
Table 1. Tree-ring sampling sites and meteorological stations.

\begin{tabular}{llrrrrr}
\hline & Name & $\begin{array}{r}\text { Longitude } \\
(\mathrm{E})\end{array}$ & $\begin{array}{r}\text { Latitude } \\
(\mathrm{N})\end{array}$ & $\begin{array}{r}\text { Elevation } \\
(\mathrm{m} \text { a.s.1. })\end{array}$ & $\begin{array}{r}\text { Time } \\
\text { span }\end{array}$ & $\begin{array}{r}\text { Cores } \\
\text { (trees) }\end{array}$ \\
\hline Tree-ring & Hy0 & 99.70 & 38.69 & $3371-3489$ & $450-2009$ & $64(27)$ \\
sites & Hy1 & 99.68 & 38.70 & $3300-3420$ & $486-2012$ & $80(39)$ \\
& Hy3 & 99.69 & 38.71 & $3301-3341$ & $490-2009$ & $24(11)$ \\
& Hy6 & 99.67 & 38.72 & $3369-3578$ & $1076-2012$ & $82(41)$ \\
\hline \multirow{2}{*}{$\begin{array}{lllll}\text { Meteorological } \\
\text { stations }\end{array}$} & Yeniugou & 99.58 & 38.42 & 3320.0 & $1960-2013$ & \\
& Zhangye & 100.43 & 38.93 & 1482.7 & $1951-2013$ & \\
\hline
\end{tabular}

\subsection{Climatic data}

Four climatic variables from two meteorological stations (Yeniugou and Zhangye) near our tree-ring sites were used here (Table 1$)$, including monthly mean temperature $\left(T_{\text {mean }}\right)$, monthly mean minimum temperature $\left(T_{\min }\right)$, monthly mean maximum temperature $\left(T_{\max }\right)$, which are means of daily minimum and maximum temperature values, and monthly total precipitation (PRCP) (Fig. 2), obtained from the China Meteorological Data Sharing Service System (http://cdc.cma.gov. $\mathrm{cn} /$ home.do). Compared to the climate variables at a single station, the two-station means of the climate variable have better spatial representation. Therefore, we also calculated the average values of the monthly climate variable between the two stations for the common period of 19602012. Because of the distinct difference in elevation between the Zhangye and Yeniugou stations, the two-station means of monthly temperature and precipitation were calculated using the monthly temperature anomalies and precipitation anomalies, respectively. In other words, departures from the 19602012 means were first calculated for each station, and then averaged for the two stations to obtain the anomaly series. It is noted that the nearest meteorological station before 2012 was Sunan station; however, its climatic data now are unavailable in the China Meteorological Data Sharing Service System, and accordingly, this station is not considered in this study.

To assess the regional significance of our reconstruction, the CRU gridded data set (TS3.21) (Mitchell and Jones, 2005) was correlated with the instrumental and reconstructed series, respectively, using the research tool known as KNMI Climate Explorer (http://climexp.knmi.nl; last access: 15 May 2014).

\subsection{Statistical methods}

Correlation and response-function analyses (Fritts, 1976) were used to investigate the relationships between the tree-ring data and climatic variables using the DENDEOCLIM2002 program (Biondi and Waikul, 2004). Partial correlation analysis was employed to separate the confounding influence of the inter-correlation of temperature and precip- itation using the SEASCORR program (Meko, 2011). Correlation coefficients and response-function coefficients between the tree-ring and climatic variables were calculated for the 12-month period extending from October of the previous year to September of the current year. Correlations and partial correlations between the tree-ring chronology and climatic variables were also calculated for various multi-month periods and on a full-year scale.

To reconstruct the past climate variations, the instrumental climatic records were regressed against the HY chronology. We examined all the subsets of the climate variables for the successive months from the previous October to the current September to identify the best climatic variable and season for reconstruction. Split-sample calibration-verification and leave-one-out cross verification methods (Michaelsen, 1987) were used to validate the calibration function. The evaluative statistics included Pearson's correlation coefficient $(r)$, the explained variance $\left(R^{2}\right)$, the sign test (ST), the firstdifferences sign test (FST), the product-mean test (PMT), the reduction of error (RE) (Fritts, 1976), and the coefficient of efficiency (CE) (Cook et al., 1999).

Wavelet analysis, using a Morlet wavelet coupled with a $5 \%$ red-noise reduction, was employed to reveal the variability of the temperature reconstruction in the frequency domain (http://paos.colorado.edu/research/wavelets/; Torrence and Compo, 1998).

\section{Results}

\subsection{STD chronology statistics}

The chronology covers the period from AD 450 to 2012 (Fig. 3). Based on the subsample signal strength (SSS) threshold of 0.85 , the chronology was considered reliable when the sample size reached 11 cores, corresponding to the period from AD 670 to 2012. The median segment length of the chronology was 516 years, indicating its ability to resolve inter-annual- to centennial-scale variations in tree growth that were likely related to climate variability. The mean sensitivity was approximately 0.175 , which was relatively low due to the criteria applied in selecting the sample cores used in chronology construction. The signal-to-noise 


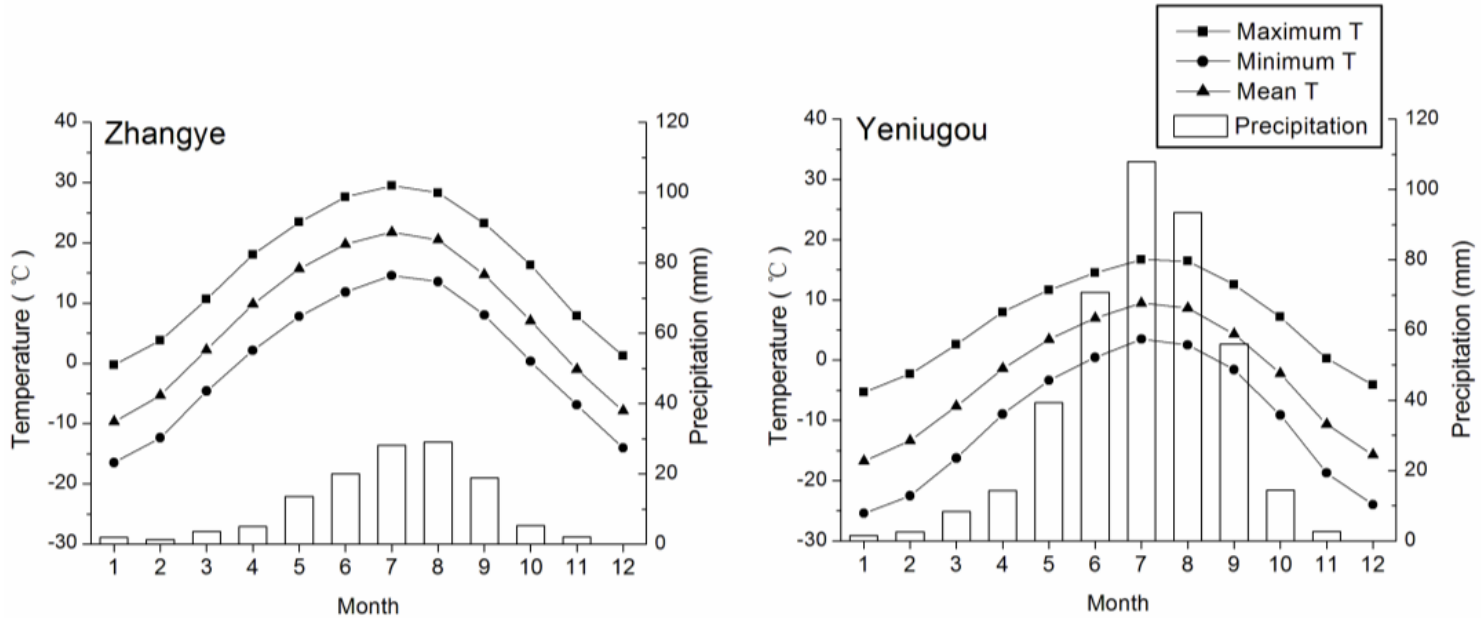

Figure 2. Monthly maximum, minimum, and mean temperatures and precipitation at the Zhangye and Yeniugou stations.

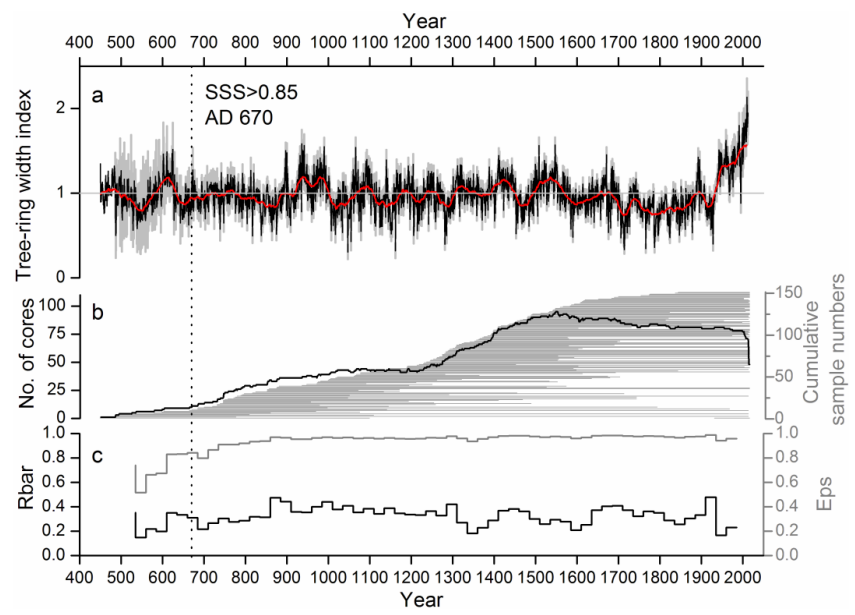

Figure 3. (a) Ring-width chronology (HY), the red line indicates the 31-year running mean, the grey area indicates the 2-standard errors of the ring-width chronology. (b) Changing sample size over time (dark line) and cumulative sample numbers. (c) EPS and $R_{\text {bar }}$ values. The dotted vertical line denotes the year AD 670, when the SSS value exceeded the threshold of 0.85 (SSS means the subsample signal strength)

ratio and the expressed population signal were 30.83 and 0.969 , respectively, indicating that the chronology was appropriate for dendroclimatic studies (Wigley et al., 1984).

\subsection{Correlation and response-function analyses between tree growth and climate}

Except for the negative correlation between the tree-ring chronology and $T_{\max }$ at Yeniugou during May of the current year, all of the temperature variables were positively correlated with the tree-ring index. Significant positive correlations with $T_{\text {mean }}$ and $T_{\min }$ occurred in almost all months
(Fig. 4). In general, the correlation coefficients between the tree-ring index and $T_{\min }$ at the two stations were stronger than those between the tree-ring index and $T_{\text {mean }}$ or $T_{\max }$. The correlations between the tree-ring index and PRCP were weak and not statistically significant in most months, except for a positive correlation in the current March and current May at Yeniugou and the current January at Zhangye.

The response-function analysis showed a similar pattern (Fig. 4). The tree-ring index was not significantly correlated with PRCP at the two stations in all months, while the monthly temperature variables in most months were positively correlated with the tree-ring index. The most significant relationships occurred in February, June and July of the current year.

The results of correlation and response-function analyses of the mean temperature variables of the two stations with a tree-ring index were very similar to those for the single stations (Fig. 4, bottom), and the relationships between the two-station average $T_{\min }$ anomalies at Zhangye and Yeniugou and the tree-ring index for different months were generally stronger than the others, indicating that $T_{\min }$ is more likely to be the control factor of radial growth of trees in this region.

Figure 5 showed the results of correlation and partial correlation analyses between the tree-ring index and the twostation average $T_{\min }$ and PRCP anomalies of Zhangye and Yeniugou at different timescales. We found statistically significant relationships between the tree-ring data and $T_{\min }$ in different months and multi-month periods (Fig. 5a). The correlation between the tree-ring index and $T_{\min }$ became stronger as the length of the averaging period increased, reaching its maximum value for the 8 -month period ending in August of the current year for the period of 1962-2012 $(r=0.78, p<0.01)$.

When $T_{\min }$ was the control variable, the relationships between the tree-ring index and precipitation were weak and 

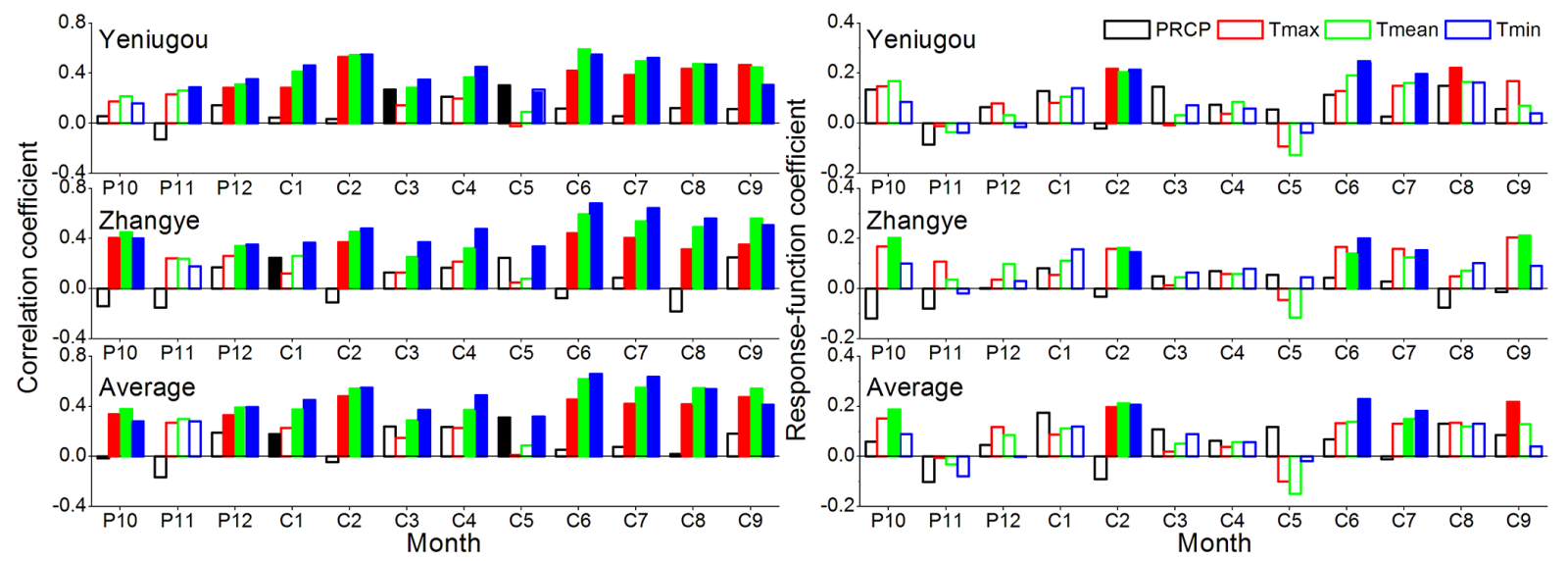

Figure 4. Correlation (left) and response-function (right) analysis plots between the HY chronology and the monthly climatic data from Yeniugou (top), Zhangye (middle) and the averages of the two stations (bottom). Months P10 through to P12 are October through to December of the previous year, and months C1 through to C9 are January through to September of the current year. The filled colour bars mean the significance level of 0.05 . The monthly climatic data include monthly mean temperature $\left(T_{\text {mean }}\right)$, monthly minimum temperature $\left(T_{\text {min }}\right)$, monthly maximum temperature $\left(T_{\max }\right)$, and monthly total precipitation $(\mathrm{PRCP})$.

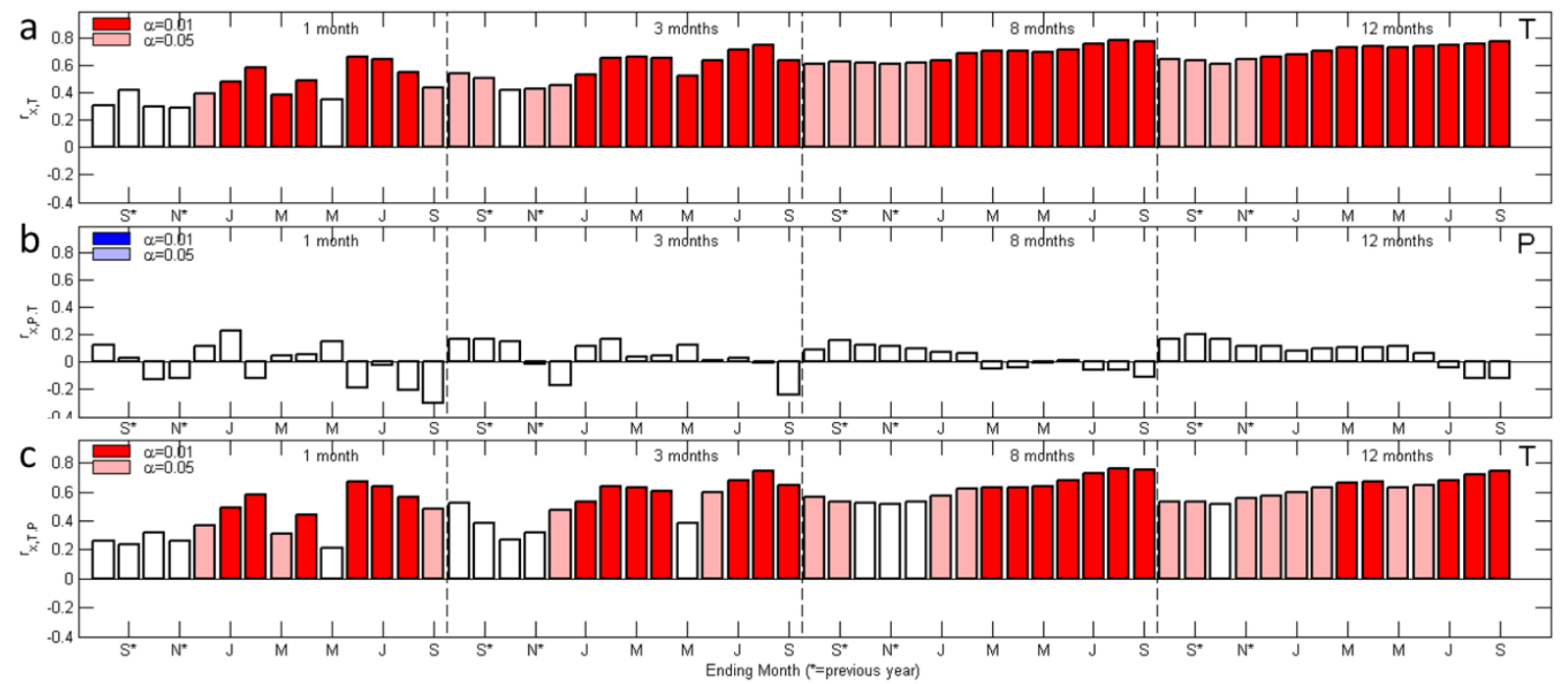

Figure 5. Correlations and partial correlations between the tree-ring series and the multi-month averages of climatic variables from Yeniugou and Zhangye. (a) Simple correlations with the primary climatic variable, the mean minimum temperature anomalies of the two stations (Zhangye and Yeniugou). (b) Partial correlations between the tree-ring index and the secondary climatic variable, the mean precipitation anomalies of the two stations, when the minimum temperature was the control variable. (c) Partial correlations between the tree-ring index and the secondary climatic variable, the mean minimum temperature anomalies of the two stations, when the mean precipitation anomalies was the control variable. The $x$ axis presents months from August of the previous year to September of the current year.

not statistically significant at the 0.05 level for the 1-, 3-, 8-, and 12-month periods (Fig. 5b). Inversely, if we used precipitation as the control variable, $T_{\min }$ had consistently strong relationships with the tree-ring data for these periods (Fig. 5c). Based on the above results, we can conclude that our treering series represented the temperature variation in the study area, especially the variation of $T_{\min }$.

\subsection{Calibration and reconstruction of the January-August $\boldsymbol{T}_{\min }$}

Based on the above analyses, we selected the two-station average January-August $T_{\min }$ anomalies of Zhangye and Yeniugou as the variable for reconstruction $(r=0.76$, with the tree-ring series for the period of 1960-2012; $p<0.01)$. The transfer function was estimated by linear regression using the two-station average January-August $T_{\min }$ anomalies of 
Zhangye and Yeniugou $\left(T_{\mathrm{c} 18}\right)$ as the dependent variable and the standard tree-ring chronology (STD) as the independent variable

$T_{\mathrm{c} 18}=-3.88+2.67 \mathrm{STD}$,

where $T_{\mathrm{c} 18}$ are the two-station average January-August $T_{\min }$ anomalies of Zhangye and Yeniugou, and STD is the index of the HY chronology. We also experimented with other seasonal and annual temperature variables for reconstruction, but the results of regression analysis and the statistics of both the split-sample test and the leave-one-out test showed that the regression model based on the two-station mean of January-August $T_{\min }$ anomalies was more reliable.

The final calibration model accounted for $58 \%(p<0.01)$ of the total variance of the two-station average JanuaryAugust $T_{\min }$ over the calibration period from 1960 to 2012 (Fig. 6a). As shown in Table 3, the ST and PMT statistics were significant at the 0.01 level, and FST was significant at the 0.05 level. The leave-one-out correlation coefficient is 0.74 , indicating a good match between the observed and predicted values. Additionally, the RE statistic (0.54) was greater than 0.3 over the full calibration period (19602012). Fig. 6b showed the observed and reconstructed $T_{\min }$ series during 1960-2012. It can be seen that the reconstructed values matched the observed values particularly well after 1985, while the agreement between the observed and reconstructed series was not as good before 1985, especially during 1975-1984. For this reason, we performed split-period verifications using data for 1960-1984 and 1960-1974, for the regression model obtained from the independent calibration period of 1985-2012 (Table 3). While the model itself had a respectable $r$ value of 0.845 , the verification period of 1960-1984 produced a relatively high reduction of error (RE) at 0.619 , and the overall sign test (ST) passed the $99 \%$ confidence level. These all indicate the overall reliability of the model. However, the verification $r$ was low (0.213) for 1960-1984, and the coefficient of efficiency (CE) was negative. Additionally, the sign test for the first-order difference (FST) did not pass the $95 \%$ confidence level, suggesting poor predicting power of the model in the high-frequency domain. After eliminating the data during 1975-1984, there were slightly improved verification results ( $r$ increased from 0.213 to 0.219 , RE increased from 0.619 to 0.679 , and CE became less negative), but the result of FST still did not reach the $95 \%$ confidence level.

Regardless of the issues in the earlier part of the calibration period, the evaluative statistics in Table 3 indicated that our regression model was stable and reliable, and was acceptable for reconstructing the interannual-to-centennial variability of the two-station average January-August $T_{\min }$ anomalies in the central Qilian Mountains since AD 670. Results of the split verification suggested that the reconstructed temperature series should be more reliable in reflecting lowfrequency (multi-year and longer timescale) variation patterns.
Table 2. Statistical features of the HY chronology.

\begin{tabular}{ll}
\hline Statistics & HY \\
\hline Total number of cores & 152 \\
Mean sensitivity & 0.175 \\
Mean & 0.982 \\
Standard deviation & 0.22 \\
First-order autocorrelation & 0.535 \\
Median length & 516 \\
Statistical features of the common-period analyses (1701-2000) \\
Number of cores & 68 \\
Mean correlation between all series & 0.312 \\
Mean correlation between trees & 0.306 \\
Mean correlation within trees & 0.823 \\
Signal-to-noise ratio & 30.83 \\
Variance explained by the first principal component $(\%)$ & 40.9 \\
Expressed population signal (EPS) & 0.969 \\
First year of subsample signal strength greater than 0.85 & $670(11)$ \\
(number of cores) & \\
\hline
\end{tabular}

The 31-year running means of the reconstructed series revealed multi-decadal- to centennial-scale variation patterns (Fig. 7a). The January-August minimum temperature anomalies fluctuated with relatively low variability from approximately AD 670 to 780 and from AD 1100 to 1400 , while some larger fluctuations were found in the periods of approximately AD 850-1100 and AD 1400-1600. A significant long-term cooling occurred with several short warmer periods, from the late 1500 s to the end of the 19th century. The January-August $T_{\min }$ increased gradually after AD 1850 , and the increase during the most recent 100 years was the most rapid in the past millennium with a warming trend of $0.26^{\circ}$ per 100 years. Based on the overall mean and 31-year running means, several distinct warm and cold periods were identified. The warm periods included approximately AD 920-1000, 1310-1450, 1490-1570, and 1930-2012, while the cold periods were approximately AD 780-890, 1000-1060, 1110-1170, 1260-1300, 1450-1490, 1570-1650, 1690-1880, and 1900-1930. The most recent 50 years was the warmest period, and AD 910-1000 was the second-warmest period over the past 1342 years. The period from $\mathrm{AD} 1690$ to 1880 was the coldest period over the past millennium (Fig. 7a). The results of wavelet analysis revealed persistent high-frequency patterns of approximately 2-4 years (mainly existing from AD 1000 to 1600), and lowfrequency centennial-scale patterns of approximately 90-170 years (mainly existing from AD 1350 to 1700) and 40-50 years (existing from AD 900 to 1000) (Fig. 7b). 
Table 3. Leave-one-out statistics and split-sample verification for the reconstructed January-August $T_{\min }$ for the common period of $1960-$ 2012.

\begin{tabular}{|c|c|c|c|c|c|c|c|c|c|}
\hline \multicolumn{3}{|c|}{ Calibration } & \multicolumn{6}{|c|}{ Verification } & \multirow[b]{2}{*}{ PMT } \\
\hline Period & $r$ & $R^{2}$ & Period & $r$ & $\mathrm{ST}$ & FST & RE & $\mathrm{CE}$ & \\
\hline \multicolumn{10}{|c|}{ Leave-one-out } \\
\hline 1960-2012 & $0.761^{\mathrm{a}}$ & 0.58 & $1960-2012$ & $0.741^{\mathrm{a}}$ & $42^{+} / 11^{-\mathrm{a}}$ & $35^{+} / 17^{-\mathrm{b}}$ & 0.55 & & $4.19^{\mathrm{a}}$ \\
\hline \multicolumn{10}{|c|}{ Split-sample calibration-verification } \\
\hline 1985-2012 & 0.845 & & $1960-1984$ & 0.213 & $25^{+} / 0^{-\mathrm{a}}$ & $14^{+} / 10^{-}$ & 0.619 & -0.89 & \\
\hline 1985-2012 & 0.845 & & $1960-1974$ & 0.219 & $15^{+} / 0^{-\mathrm{a}}$ & $9^{+} / 5^{-}$ & 0.671 & -0.32 & \\
\hline
\end{tabular}

$r$ : Pearson's correlation coefficient; $R^{2}$ : the explained variance; ST: the sign test; FST: the first-differences sign test; PMT: the product-mean test; RE: the reduction of error; CE: the coefficient of efficiency; ${ }^{\mathrm{a}}$ significant at $P<0.01$; $^{\mathrm{b}}$ significant at $P<0.05$.
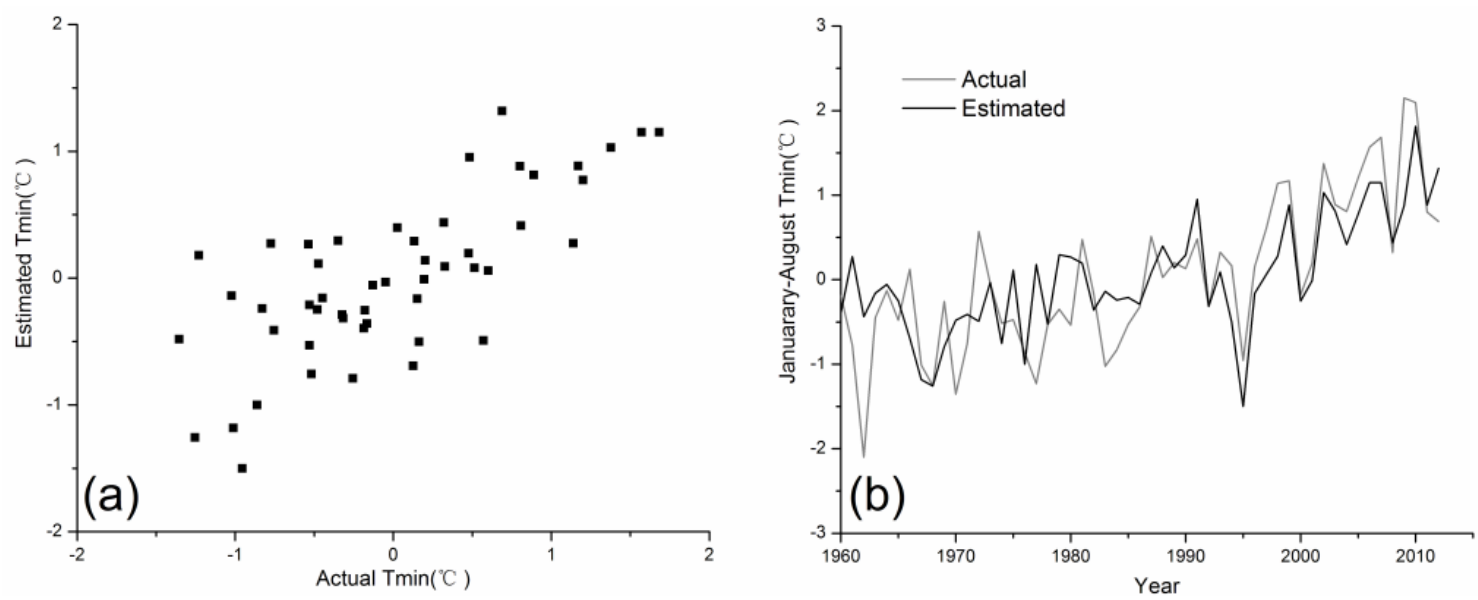

Figure 6. Scatter plot (a) and time series (b) of the actual and estimated $T_{\min }$ anomalies during the calibration period from 1960 to 2011.

\section{Discussion}

\subsection{Climatic implications of the upper treeline chronologies}

The significant positive correlations between the tree-ring data and $T_{\text {mean }}$ and $T_{\min }$ in most months (Fig. 4) indicated that the HY chronology was temperature sensitive. A similar climatic response has been reported for the timberline forests on the eastern and northeastern TP (Shao and Fan, 1999; Bräuning, 2006; Liu et al., 2007; Liang, 2006, 2009). In previous studies, $T_{\min }$ has been found to constrain radial growth in the TP (Gou et al., 2007a; Li et al., 2011b; Liang et al., 2008; Liang et al., 2010; Lv and Zhang, 2013). Even though the cambium tissues of trees are dormant in winter and early spring, the phloem sap may have freezing damages when temperatures are low during this period (Kimmins, 1987). Additionally, warmer winter $T_{\min }$ protects roots from cold damages, and hence, trees may experience increased growth in the subsequent growing season (Pederson et al., 2004). On the other hand, low summer night air temperatures $\left(T_{\min }\right)$ result in low soil temperatures, which may persist into the daytime, especially in the understory environments (Tranquillini
1979). The growth of roots and their function of water uptake will be limited by low summer soil temperatures at the timberline (Körner, 1999; Mayr, 2007). $T_{\min }$ is known to be a critical factor affecting conifer tracheid division and enlargement by changing the timing and duration of the growing season at the timberline (Deslauriers et al., 2003; Rossi et al., 2008). Therefore, monthly minimum temperature is an important climatic and ecological indicator, not only because it is one of the directly measured meteorological variables, but also because of its potential impacts on tree growth and biological activities. However, the influence of growing-season precipitation should be noted in our study region as well, because of its semi-arid climate. The positive correlations of the tree-ring index with precipitation and negative correlations with maximum temperature in May indicated the presence of moisture stress when the trees begin to grow in the early growing season. Although precipitation is higher and temperatures are lower at the upper forest limit than those at the lower elevations, rainfall during this time may not meet the demand for tree growth in the arid and semi-arid areas (Salzer and Hughes, 2007). Nevertheless, the influence of precipitation seems to occur only during the early growing season, and tree growth is mainly influenced by temperature, 


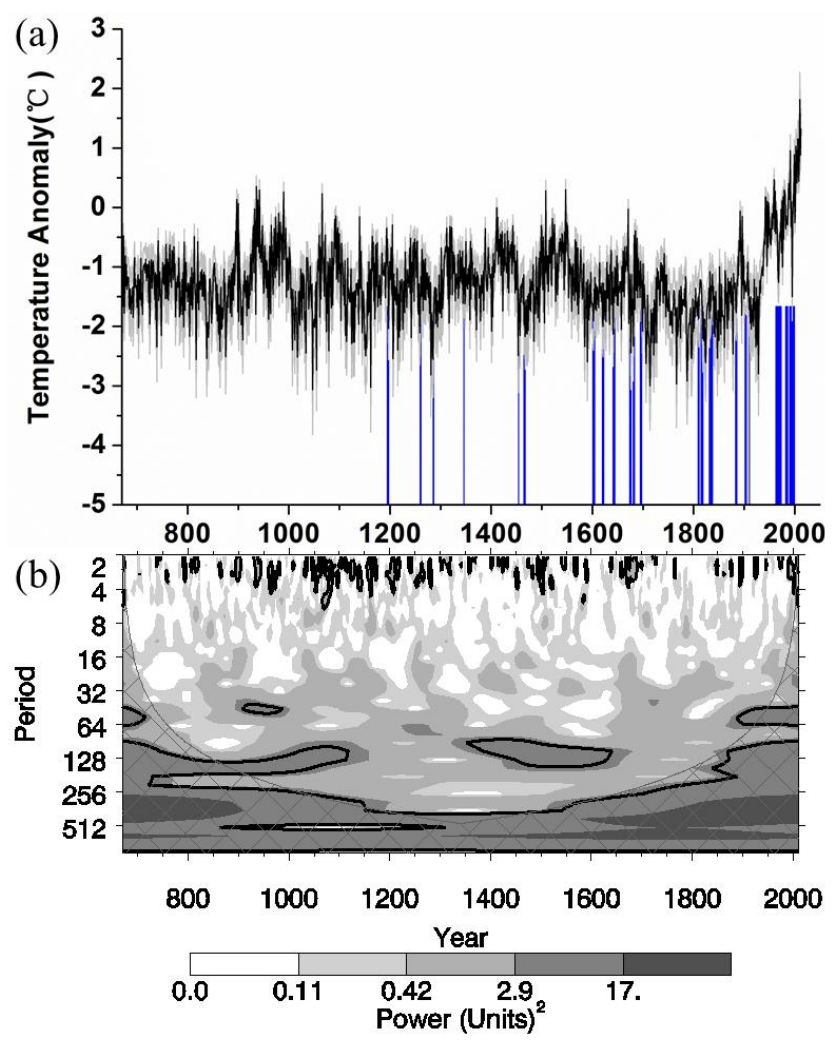

Figure 7. (a) Our reconstructed temperature in the central Qilian Mountains and $95 \%$ confidence level (grey bars), the black dark lines indicate the 31-year running mean of our reconstruction. The vertical blue lines indicate 21 volcanic events during AD 10001999. (b) The wavelet power spectrum of our temperature reconstruction series. Cross-hatched regions represent the cone of influence where zero-padding of the data was used to reduce variance using a Morlet wavelet. Black contours indicate significant modes of variance with a $5 \%$ significance level using an autoregressive lag-1 red-noise background spectrum (Torrence and Compo, 1998).

especially minimum temperature both prior to and during the growing season, at our study sites.

\subsection{Validation of the reconstruction}

\subsubsection{Comparison between instrumental and estimated data}

Figure $6 \mathrm{~b}$ showed discrepancies between the observed and predicted values by the regression model, especially during the period of 1975-1984. Such discrepancies seem to be a common problem in tree-ring-based temperature reconstructions in China, in which the agreement between observed data and estimated data became worse before the 1990s in many regions across China (Deng et al., 2013; Fan et al., 2009, 2010; Gou et al., 2007b; Lv and Zhang, 2013; Shi et al., 2010; Song et al., 2014; Yang et al., 2009b, 2010; Zhang et al., 2013; Zhu et al., 2011a). Similar issues were also found for the tree-ring-based precipitation reconstructions (Chen et al., 2011; Fan et al., 2008b; Liu et al., 2011; Shao et al., 2005; Yang et al., 2011, 2014; Y. Zhang et al., 2011; Zhang et al., 2014). In addition, the correlation coefficient of annual $T_{\text {mean }}$ between the Zhangye and Yeniugou stations for the period of 1960-1984 is 0.36, while for the period of 1985-2009, the correlation coefficient between the two stations is 0.81 . Apparently, these discrepancies could have been caused by the uncertainties in the instrumental data for the earlier years, which were resulted from inconsistent observation practices, poor quality control, and location and instrumentation changes of numerous meteorological stations before the 1990s (Ren et al., 2012). Data in more recent years have gone through rigorous quality assessment/quality control procedures, and the uncertainties in data have been significantly reduced (Ren et al., 2007).

\subsubsection{Spatial representativeness of the reconstructed series}

Figure $8 \mathrm{a}$ and $\mathrm{b}$ showed the spatial patterns of the correlations of the CRU gridded mean January-August $T_{\min }$ over western China with the actual and reconstructed JanuaryAugust $T_{\min }$ for the period 1960-2012. The instrumental data significantly $(\mathrm{p}<0.1)$ correlated with the gridded mean January-August $T_{\min }$ over the entire western China, with stronger correlations being found mainly in the TP and the northern-central part of western China (Fig. 8a). For the reconstructed series, the spatial patterns of the correlation with both gridded $T_{\min }$ (Fig. 8b) and $T_{\text {mean }}$ (Fig. 8c) were quite similar to that of the instrumental $T_{\min }$, with somewhat lower correlation coefficients and smaller spatial coverage of statistical significance. However, the TP was still a prominent area with high correlation coefficients. The spatial correlation results demonstrated that our temperature reconstruction could reflect temperature variability in a large region, especially in the TP.

\subsubsection{Comparisons with other reconstructions and Northern Hemisphere temperature}

To assess the validity of our minimum temperature reconstruction for the Qilian Mountains (Fig. 9a) further, we compared it with several millennium-long temperature reconstructions in the region. Closest to our study sites is the Sidalong reconstruction series (see Fig. 1) of December-April temperatures (Liu et al., 2007), based on a combination of ring width and stable carbon isotope with a 3-year resolution (Fig. 9b). This reconstruction agreed closely with ours (Fig. 9a), with a correlation coefficient of $0.58(p<0.01)$ between the two series for the period of AD 1066-1999, and the variation patterns were similar on the interdecadal timescale. However, some differences in the low-frequency domain exited during AD 1100-1200 and 1350-1410, which may be due to the different standardisation methods used and 

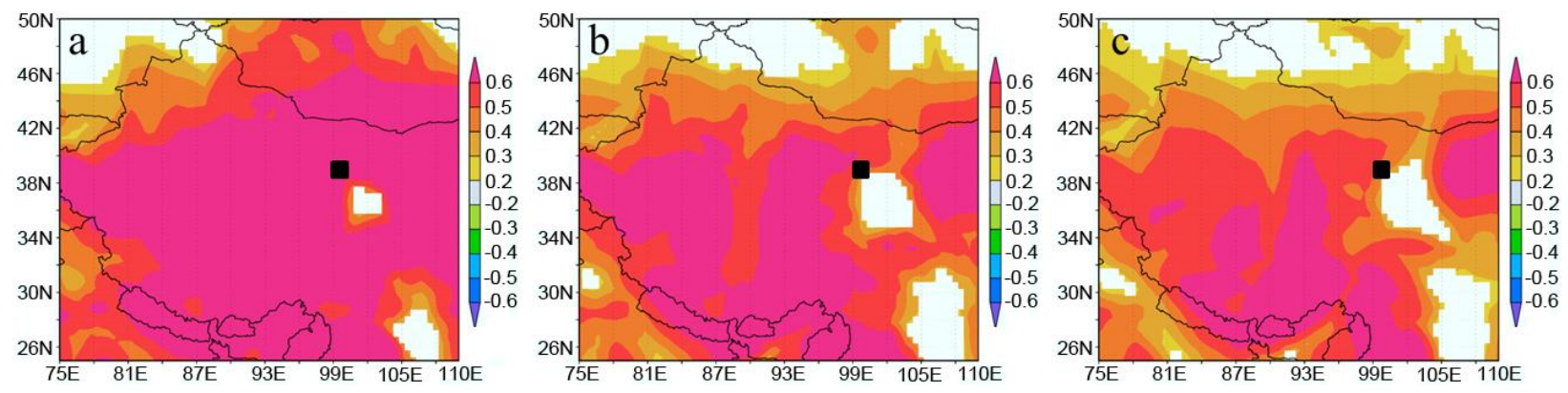

Figure 8. Correlations of the instrumental (a) and reconstructed (b) January-August $T_{\min }$ with the CRU gridded January-August $T_{\min }$ for western China during the period 1960-2012, as well as correlation of reconstructed $T_{\min }$ with the CRU gridded January-August $T_{\text {mean }}$ for the same period (c). The black square indicates the location of this study.

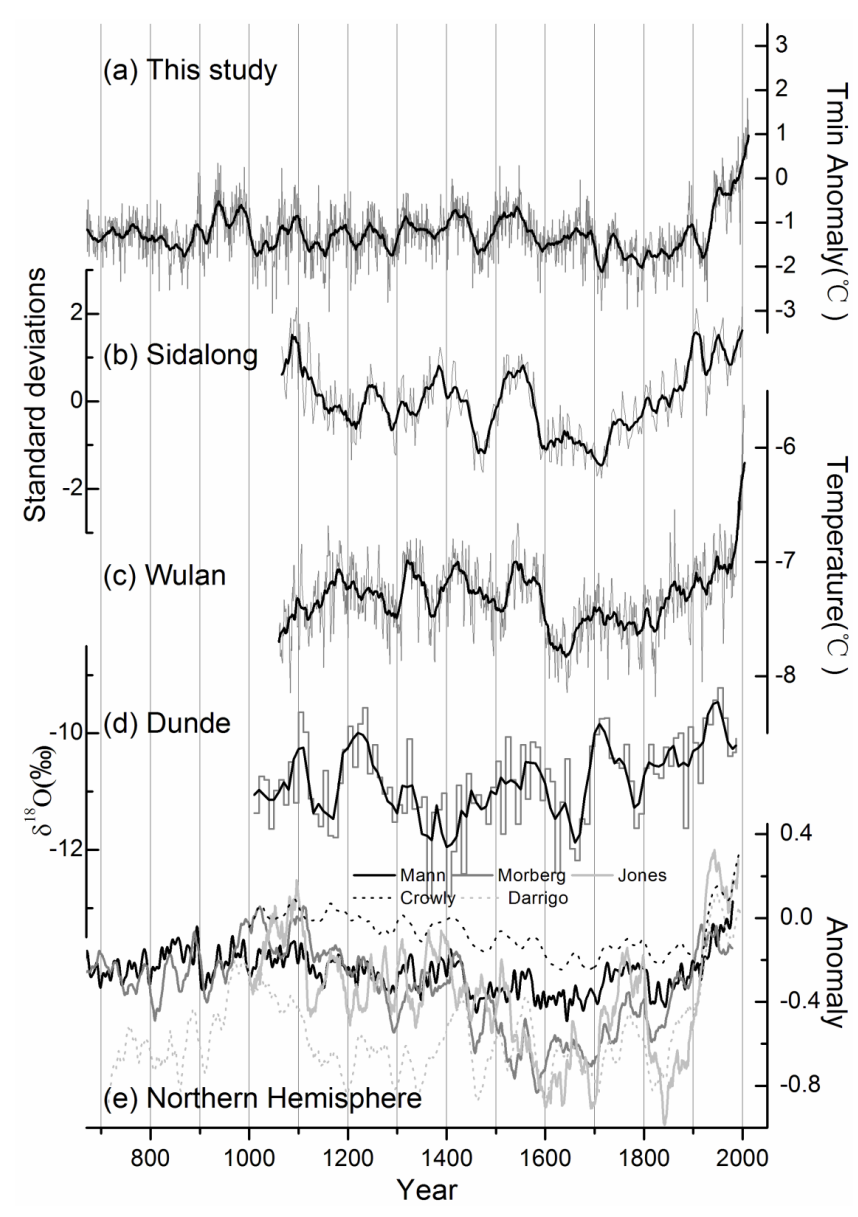

Figure 9. Comparison between the reconstruction presented here (a) and other temperature series for the Qilian Mountains (b, c, and d) (Liu et al., 2007; Zhu et al., 2008; Thompson et al., 2003), and the Northern Hemisphere (e) (Jones et al., 1998; Mann et al., 1999; Crowly, 2000; Moberg et al., 2005; D’Arrigo et al., 2006). The dark lines indicate the 20-year running mean of each series, except for the 21-year running mean of the Sidalong series (Liu et al., 2007). the response mechanisms of carbon isotope and radial growth to climate factors. Figure $9 \mathrm{c}$ shows another millennial-scale temperature reconstruction of previous September to current April (Zhu et al., 2008), using Qilian juniper samples from the upper treeline in Wulan, approximately $200 \mathrm{~km}$ south of our sites (Fig. 1). Like our temperature reconstruction, this reconstruction series indicated that cold conditions prevailed from the early 17 th century to the middle of the 19th century, and that the rate of warming rapidly increased during the most recent century. The Wulan reconstruction was also significantly correlated with our reconstruction for the period of AD 1060-2004 ( $r=0.44, p<0.01)$. This series and our series also showed consistent multi-decadal variations, such as the cold period at the end of the 13 th century, warm period during the 16th century, cool period from the end of the 16th century to the early 17 th century, and the cold period during the 1800s. The two reconstructions showed certain discrepancies in multi-decadal trends during several periods, such as AD 1100-1200. Since the differences mainly existed before AD 1200, when the sample depth of the Wulan reconstruction was low, the sample depth may have contributed to these discrepancies (Shao et al., 2010). Additionally, intra-annual variability may have caused discrepancies between the two series, as the seasons covered by the reconstructions were different (January-August vs. previous September-current April).

In addition to the tree-ring-based reconstructions, we compared our reconstruction to an ice-core $\delta^{18} \mathrm{O}$ series with a 10year resolution reflecting the temperature variations at Dunde (see Fig. 1) in the Qilian Mountains (Thompson et al., 2003) (Fig. 9d). Both series showed strong warming trends since the late 18 th century. The cold periods of approximately AD 1100-1200, 1250-1300, 1450-1500, and 1750-1800 and the warm periods of approximately AD 1050-1100, 1500-1600, and 1950-2009 in our reconstruction were all confirmed by the corresponding cold and warm periods in the ice-core series. In general, the overall agreement between our reconstruction and other temperature reconstructions suggests that our series is reliable over the past millennium. 
We also compared our reconstruction to several broadscale temperature reconstructions for the Northern Hemisphere (NH) (Jones et al., 1998; Mann et al., 1999; Crowly, 2000; Moberg et al., 2005; D’Arrigo et al., 2006). As shown in Fig. 9e, the temperature reconstructions for the NH generally showed a cold period from approximately AD 700 to 950 and a warm period from approximately AD 950 to 1100 (the Mediaeval Climate Anomaly). Another cold period can be seen during approximately AD $1100-1400$, followed by the Little Ice Age (LIA) (approximately 1450-1850). Temperature then rapidly increased after approximately AD 1810 . Our reconstruction showed a similar long-term trend of temperature variability over the past 1300 years. Certain decadalscale cold and warm episodes in the $\mathrm{NH}$, including those of the AD 840s (cold), 910s (cold), 980s (warm), 1090s (warm), 1210s (cold), 1240s (warm), 1290s (cold), 1420s (warm), 1470s (cold), 1540s (warm), 1590s (cold), 1710s (cold), and 1990s (warm), were also found in our reconstruction, suggesting that the temperature variations in the northeastern TP were highly synchronous with those of the NH. Several of these cold or warm events are represented by reconstructed temperature series in other regions. For example, the cold periods during approximately the AD 840s and 910s can be seen in a stalagmite series from Beijing (Tan et al., 2003) and in historical documents from eastern China (Ge et al., 2003). The warm periods during approximately the AD 1240s, 1540s and 1990s were recorded both in eastern China and in the TP (Yang et al., 2002, 2009b). These agreements not only suggested the occurrence of climatic events at a continental or even semi-hemispheric scale but also reinforced the validity of our temperature reconstruction. The differences between the $\mathrm{NH}$ temperature series and our reconstruction probably reflected local climatic variability. For example, our series showed that the Mediaeval warm period was not as continuous in the Qilian Mountains, and that it probably occurred earlier in this region than elsewhere in the $\mathrm{NH}$. The magnitudes of the temperature fluctuations and the multi-decadal trends during some periods also differed between our series and the NH temperature series.

\subsection{The periodicity of the reconstruction and the possible forcing factors of temperature variations}

The cycles of 2-4 years (Fig. 7b) in our reconstruction are typically associated with El Niño-Southern Oscillation (ENSO) (Allan et al., 1996); similar periodicities have been identified in other temperature and precipitation reconstruction series in China (Fang et al., 2009; Li et al., 2011a; Y. Zhang et al., 2011; Sun and Liu, 2012; Deng et al., 2013). The instrumental data-based research into ENSO and temperature in the Qilian Mountains showed that surface temperatures tend to increase during the El Niño years, while they tend to decreased during the La Niña events in this area (Lan et al., 2003; C. Zhang et al., 2011; Yang and Zhao, 2012). However, it seems that the relationship be- tween ENSO and temperature varied with time for the past millennium. Cross correlation between a reconstructed interdecadal ENSO variation series (Li et al., 2011) and our reconstruction for the period 900-2002 was not statistically significant, with lags of up to 10 years (highest $r=-0.017$, lag $=0$ ), while significant correlations between the ENSO index and reconstructed temperatures were found in certain periods using a 50-year moving correlation. A series of significant positive correlations $(p<0.01)$ were found in approximately AD 1340-1410, 1553-1631, and 1798-1869, with the highest correlation coefficient of 0.32 in AD 13551404 , and meanwhile, continuous significant negative correlations $(p<0.01)$ were found in AD 1060-1130, 15911656 , and 1840-1927, with the strongest correlation coefficient of -0.33 during AD 1849-1898.

The significant cycles at around 40-50 years (Fig. 7b) might be linked to the Pacific Decadal Oscillation (PDO) (Mantua et al., 1997; Minobe, 1997). We calculated the correlation between our reconstruction and a reconstructed PDO index (MacDonald and Case, 2005) for the period of 9931996, but the relationship between the two series was not statistically significant $(r=0.08)$. However, it was interesting to note that significantly negative correlations were found in several periods when we calculated the moving correlation between the two series for different 100-year intervals, especially in AD 1370-1510, when continuous highly negative correlation coefficients were found with the strongest correlation of $-0.564(p<0.01)$ in AD 1389-1488. Meanwhile, a series of significantly positive correlations were found in AD 1068-1210, 1282-1386, and 1509-1654, and the highest positive correlation coefficient was $0.456(p<0.01)$ for AD 1528-1627. Hence, the relationship between PDO and temperature variability in our study area probably changed over time.

It is well known that solar irradiance and volcanism are the important forcing factors of global temperature variations (Crowley, 2000; Jones and Mann, 2004). The centennial cycles identified in our study were possibly associated with the frequencies of solar variations (Stuiver and Braziunas, 1989; Raspopov et al., 2008). The cycles similar to the periodicities of 90-170 years have been found in other tree-ring reconstructions in China (Wang et al., 2008; Gou et al., 2010; Y. Zhang et al., 2011). These significant low-frequency cycles were prominent in the periods of AD 1350-1650 and before AD 1150, corresponding to the Sporer minimum (AD 1460-1550) and Oort minimum (AD 1040-1080) periods of low solar activities. Although the low-frequency signal has been depressed since AD 1650, low temperatures during the LIA should be linked to the Maunder Minimum of solar activity (Shindell et al., 2001).

Several extreme cold events in our reconstruction can be linked to volcanic eruptions. Because the effects of some eruptions may take a couple of years to impact the globe (Robock and Mao, 1995; Salzer and Hughes, 2007), the reconstructed cold events which occurred in the concurrent 
Table 4. Tropical volcanic eruptions and the possible corresponding cold events recorded by tree rings (AD 1000-1999).

\begin{tabular}{|c|c|c|c|}
\hline & $\begin{array}{l}\text { Year (tropical volcanic radiative } \\
\text { forcing, } \mathrm{W} \mathrm{m}^{-2} \text { ) (Mann et al., 2005) }\end{array}$ & Year (standardised $T_{\min }$ ) & Volcanic eruption* \\
\hline 1 & $1195(-2.42), 1196(-0.9)$ & $1197(<-1.5), 1198(<-1)$ & \\
\hline 2 & $1259(-11.82), 1260(-4.4), 1261(-1.6)$ & $\begin{array}{l}1259(<-1.5), 1260(<-0.5) \\
1262(<-0.5)\end{array}$ & \\
\hline 3 & $1285(-3.75), 1286(-1.4)$ & $1285(<-1.5), 1286(<-0.5)$ & \\
\hline 4 & $1453(-4.4)$ & $1453(<-1.5)$ & \\
\hline 5 & $1465(-1.1), 1466(-0.4)$ & $\begin{array}{l}1465(<-1), 1467(<-1.5) \\
1468(<-0.5)\end{array}$ & \\
\hline 6 & $1601(-5.43), 1602(-2)$ & $1602(<-1)$ & \\
\hline 7 & $1641(-5.5), 1642(-2), 1643(-0.8)$ & $1641(<-1), 1643(<-0.5)$ & $\begin{array}{l}\text { Philippines - Mindanao (4 January 1641) } \\
\text { Java (Indonesia) (1641) }\end{array}$ \\
\hline 8 & $1674(-3.37), 1675(-1.2)$ & $\begin{array}{l}1674(<-0.5), 1675(<-1), \\
1676(<-1.5)\end{array}$ & \\
\hline 9 & $1681(-2.79)$ & $1681(<-1.5)$ & \\
\hline 10 & $1809(-5.5), 1810(-2)$ & $1810(<-1)$ & \\
\hline 11 & $1815(-5.98), 1816(-2.2), 1817(-0.8)$ & $1818(<-1)$ & $\begin{array}{l}\text { Lesser Sunda Islands (Indonesia) (10 April 1815) } \\
\text { Java (Indonesia) (17 January 1817) }\end{array}$ \\
\hline 12 & $1831(-4.86), 1832(-1.8)$ & $1831(<-1.5), 1833(<-0.5)$ & North of Luzon (Philippines) (1831) \\
\hline 13 & $1883(-3.7), 1884(-1.4)$ & $1883(<-1.5), 1884(<-1.5)$ & Indonesia (27 August 1883) \\
\hline 14 & $1969(-1.06), 1970(-0.51), 1971(-0.2)$ & $1971(<-0.5)$ & $\begin{array}{l}\text { Java (Indonesia) (17 May 1982) } \\
\text { Sulawesi (Indonesia) (23 July 1983) }\end{array}$ \\
\hline 15 & $1993(-1.39), 1994(-0.56), 1995(-0.26)$ & $1995(<-1.5)$ & $\begin{array}{l}\text { Northern Chile (19 April 1993), } \\
\text { New Britain (19 September 1994) }\end{array}$ \\
\hline
\end{tabular}

* Volcanic eruption data were downloaded from the Global Volcanism Program, Department of Mineral Sciences, National Museum of Natural History, Smithsonian Institution (http://www.volcano.si.edu/).

year and/or the next two years of volcano eruptions were listed (Table 4). The tropical volcanic radiative forcing (Mann et al., 2005) was used here to represent volcanic activities, and a single negative value year or successive negative value years was regarded as a volcanic event. In this way, 21 volcanic events were then identified during the period of AD 1000-1999 (Fig. 7). Meanwhile, our reconstruction series was normalised by its mean and standard deviation, so that the years with a value lower than 0.5 were regarded as cold years in this standardised series. We found that 15 out of 21 volcanic event years for the past millennium were corresponding to cold years in the reconstructed minimum temperature series (Table 4). Some of them were also supported by the factual evidences, such as the volcanic eruptions since AD 1815. It seems that the volcanic eruptions in Indonesia played an important role in temperature variation in our study area. Undoubtedly, solar activity and volcanism have great influences on global temperature change. However, the forcing mechanisms of both factors on local temperature variations are complex and still unclear. More temperature-related tree-ring series are urgently needed for further analysis.

\section{Conclusions}

In this study, we sampled four upper-treeline sites (> $3300 \mathrm{~m}$ a.s.l.) for tree-ring cores of Qilain juniper in the
Qilian Mountains of the northeastern Tibetan Plateau. After carefully screening sample cores that are less sensitive to precipitation, we selected 152 cores from 82 trees to construct a 1342-year tree-ring width chronology. Correlation and response-function analyses between the chronology and climatic variables $\left(T_{\max }, T_{\min }, T_{\text {mean }}\right.$, and PRCP) revealed that the radial growth of the trees was mostly controlled by temperature, especially $T_{\min }$. The correlations between the tree-ring chronology and mean minimum temperatures at nearby weather stations can be as high as 0.76 and, therefore, the chronology can be used to infer the variations in two-station average January-August $T_{\min }$ over the past millennium for the study region. For the calibration period of 1960-2012, the transfer function explained $58 \%$ of the total variance in mean January-August $T_{\min }$. This temperature reconstruction covered the period AD 670-2012 and revealed temperature variation patterns at the inter-annual to centennial timescales over the past 1343 years. The comparisons with other reconstructions in the region and those of the Northern Hemisphere displayed strong consistencies, suggesting good reliability.

According to the reconstructed series, distinct warm periods were identified in AD 920-1000, 1310-1450, 14901570, and 1930-2012, while cool periods were identified in AD 780-890, 1000-1060, 1110-1170, 1260-1300, 14501490, 1570-1650, 1690-1880, and 1900-1930. The warming 
during the most recent 50 years was unprecedented within the past millennium. Even during the dramatic warming from AD 900 to 1100, the reconstructed temperatures did not exceed those observed at the present time. The period from $\mathrm{AD}$ 1690 to 1880 was the coldest and longest-lasting cold period during the past 1343 years.

Significant periodicities were found in the reconstructed series using the wavelet analysis, including those of $2-4$, $40-50$, and $90-170$ years. We examined the relationships between the reconstructed temperature series and several forcing mechanisms of temperature variability at different temporal scales, including ENSO and PDO, solar activities, and volcanic eruption records. We found that the influences of both ENSO and PDO might have been variable over time. The periodicities of solar activity have good agreement with those in our reconstruction. The tropical volcanic eruptions also have good corresponding relationships with the cold events recorded by our reconstruction.

Using site-specific sampling strategy and sample selection processes, the Qilian juniper on the upper treeline can preserve well the signals of temperature variations for the past millennium in the semi-arid Qilian Mountains. Our 1343year reconstruction of minimum temperature can be used in future climatic and/or ecological studies as an indicator of environmental change. However, more attention should be paid to the quality of instrumental data in future studies, when we investigate the climatic implications of tree-ring data. Furthermore, some discrepancies between our reconstruction and other records, as well as the variable relationships between temperature and the forcing factors (such as ENSO, PDO, solar activity, and volcanic eruptions), indicate that more millennium-long tree-ring records sensitive to temperature variations in different areas are needed to understand the regional temperature change and its forcing mechanisms better.

Acknowledgements. We are very grateful to two anonymous referees whose comments helped improve the final manuscript. Thanks to Samuli Helama, Tao Pan, Haifeng Zhu and PhD student Sébastien Guillet for their kind help in the study. This research was supported by the National Basic Research Program of China “973” programme (2010CB950101), "One-Three-Five" Strategic Planning of CAS (2012ZD001), the Strategic Priority Research Program (XDA05080201) from the Chinese Academy of Sciences, the China Special Fund for Meteorological Research in the Public Interest (GYHY201106013-2), and the University of San Diego (FRG \#2012-13 and \#2013-14).

Edited by: S. Bronnimann

\section{References}

Allan, R., Lindesay, J., and Parker, D.: El Niño-Southern Oscillation and climatic variability, Common wealth Scientific and Industrial Research Organisation, Melbourne, Vicoria, Australia, 405, 1996.

Biondi, F. and Waikul, K.: DENDROCLIM2002: a C++ Program for statistical calibration of climate signals in tree-ring chronologies, Comput. Geosci., 30, 301-311, 2004.

Bräuning, A.: Tree-ring evidence of "Little Ice Age" glacier advances in southern Tibet, Holocene, 16, 369-380, 2006.

Chen, C. Y.: The distribution of climate and vegetation in the north slope of the Qilian Mountains, Arid Meteorol., 2, 28-33, 1990 (in Chinese).

Chen, F., Yuan, Y., and Wei, W.: Climatic response of Picea crassifolia tree-ring parameters and precipitation reconstruction in the western Qilian Mountains, China, J. Arid Environ., 75, 11211128, 2011.

Cheng, G. and Wu, T.: Responses of permafrost to climate change and their environmental significance, Qinghai-Tibet Plateau, J Geophys. Res., 112, F02S03, doi:10.1029/2006JF000631,2007.

Cook, E. R.: A time-series analysis approach to tree-ring standardization, $\mathrm{PhD}$ dissertation, The University of Arizona, Tucson, 1985.

Cook, E. R. and Kairiukstis, L. A.: Methods of dendrochronology: Applications in the environmental sciences, Kluwer Academic Publishers, Dordrecht, The Netherlands, 1990.

Cook, E. R., Krusic, P. J., and Jones, P. D.: Dendroclimatic signals in long tree-ring chronologies from the Himalayas of Nepal, Int J. Climat., 23, 707-732, 2003

Cook, E. R., Meko, D. M., Stahle, D. W., Cleaveland, M. K.: Drought reconstructions for the continental United States, J. Climate, 12 (4), 1145-1162, 1999.

Crowley, T. J.: Causes of Climate Change Over the Past 1000 Years, Science, 289, 270-277, 2000.

Cyranoski, D.: The long-range forecast, Nature, 438, 275-276, 2005.

D’Arrigo, R., Wilson, R., and Jacoby, G.: On the long-term context for late twentieth century warming, J. Geophys. Res., 111, D03103, doi:10.1029/2005JD006352, 2006.

Deng, Y., Gou, X., Gao, L., Yang, T., and Yang, M.: Early-summer temperature variations over the past $563 \mathrm{yr}$ inferred from tree rings in the Shaluli Mountains, southeastern Tibet Plateau, Quat Res., 81, 513-519, doi:10.1016/j.yqres.2013.08.002, 2013.

Deslauriers, A., Morin, H., and Begin, Y.: Cellular phenology of annual ring formation of Abies balsamea in the Quebec boreal forest (Canada), Can. J. For. Res., 33, 190-200, 2003.

Di Filippo, A., Biondi, F., Cufar K., de Luis, M., Grabner, M., Maugeri, M., Saba, P. E., Schirone, B., and Piovesan, G.: Bioclimatology of beech (Fagus sylvatica L.) in the Eastern Alps: spatial and altitudinal climatic signals identified through a treering network, J. Biogeogr., 34, 1873-1892, 2007.

Ding, Y. H.: Summer monsoon rainfalls in China, J. Meteor. Soc. Japan., 70, 373-396, 1992.

Esper, J., Frank, D. C., Timonen, M., Zorita, E., Wilson, R. J. S., Luterbacher, J., Holzkämper, S., Fischer, N., Wagner, S., Nievergelt, D., and Versteg, A.: Orbital forcing of tree-ring data, Nat Clim. Change., 2, 862-866, doi:10.1038/nclimate1589, 2012.

Fan, Z.-X., Bräuning, A., and Cao, K.-F.: Annual temperature reconstruction in the central Hengduan Mountains, China, 
as deduced from tree rings, Dendrochronologia, 26, 97-107, doi:10.1016/j.dendro.2008.01.003, 2008a.

Fan, Z.-X., Bräuning, A., and Cao, K.-F.: Tree-ring based drought reconstruction in the central Hengduan Mountains region (China) since A.D. 1655, Int. J. Climatol., 28, 1879-1887, 2008 b.

Fan, Z.-X., Bräuning, A., Yang, B., and Cao, K.-F.: Tree ring density-based summer temperature reconstruction for the central Hengduan Mountains in southern China, Glob. Planet. Chang., 65, 1-11, 2009.

Fan, Z.-X., Bräuning, A., Tian, Q.-H., Yang, B., and Cao, K.F.: Tree ring recorded May-August temperature variations since A.D. 1585 in the Gaoligong Mountains, southeastern Tibetan Plateau, Palaeogeogr. Palaeocl., 296, 94-102, 2010.

Fang, K., Gou, X., Chen, F., Yang, M., L, J., He, M., Zhang, Y., Tian, Q., and Peng, J.: Drought variations in the eastern part of northwest China over the past two centuries: evidence from tree rings, Clim. Res., 38, 129-135, 2009.

Fritts, H. C.: Tree Rings and Climate, London, Academic Press, 1976.

Ge, Q. S., Zheng, J. Y., Fang, X. Q., Ma, Z. M., Zhang, X. Q., Zhang, P. Y., and Wang, W. C.: Winter half-year temperature reconstruction for the middle and lower reaches of yellow river and Yangtze river, China, during the past 2000 years, Holocene, 13, 933-940, 2003.

Ge, Q. S., Zheng, J. Y., Hao, Z. X., Shao, X. M., Wang, W. C., and Luterbacher, J.: Temperature variation through 2000 years in China: An uncertainty analysis of reconstruction and regional difference, Geophys. Res. Lett., 37, L03703, doi:10.1029/2009GL041281, 2010.

Gou, X., Chen, F., Jacoby, G., Cook, E., Yang, M., Peng, J., and Zhang, Y.: Rapid tree growth with respect to the last 400 years in response to climate warming, northeastern Tibetan Plateau, Int. J. Climat., 27, 1497-1503, doi:10.1002/joc.1480, 2007a.

Gou, X., Chen, F., Yang, M., Jacoby, G., Fang, K., and Tian, Q.: Asymmetric variability between maximum and minimum temperatures in Northeastern Tibetan Plateau: Evidence from tree rings, Sci. China. Ser. D., 50, 1-15, 2007 b.

Gou, X., Deng, Y., Chen, F., Yang, M., Fang, K., Gao, L., Yang, T., and Zhang, F.: Tree ring based streamflow reconstruction for the Upper Yellow River over the past 1234 years, Chin. Sci. Bull., 55, 4179-4186, 2010.

Grissino-Mayer, H. D.: Evaluating crossdating accuracy: A manual and tutorial for the computer program cofecha, Tree-Ring Res., 57, 205-221, 2001.

Holmes, R. L.: Computer-assisted quality control in tree-ring dating and measurement, Tree-Ring Bulletin, 43, 69-95, 1983.

Hughes, M. K.: An improved reconstruction of summer temperature at Srinagar, Kashmir since $1660 \mathrm{AD}$, based on tree-ring width and maximum latewood density of Abies pindrow (Royle) Spach, Palaeobotanist., 50, 13-19, 2001.

Jones, P. D. and Mann, M. E.: Climate over past millennia. Rev. Geophys., 42, RG2002, doi:10.1029/2003RG000143, 2004.

Jones, P. D., Briffa, K. R., Barnett, T. P., and Tett, S. F. B.: Highresolution palaeoclimatic records for the last millennium: interpretation, integration and comparison with General Circulation Model control-run temperatures, Holocene, 8, 455-471, 1998.

Jones, P. D., Briffa, K. R., Osborn, T. J., Lough, J. M., van Ommen, T., Vinther, B. M., Luterbacher, J., Zwiers, F. W., Wahl, E., Schmidt, G., Ammann, C., Mann, M. E., Wanner, H., Buck- ley, B. M., Cobb, K., Esper, J., Goosse, H., Graham, N., Jansen, E., Kiefer, T., Kull, C., Mosley-Thompson, E., Overpeck, J. T., Schulz, M., Tudhope, S., Villalba, R., and Wolff, E.: Highresolution paleoclimatology of the last millennium: a review of the current status and future prospects, Holocene, 19, 3-49, 2009.

Kimmins, J. P.: Forest Ecology, MacMillan Publishing Company, New York, 1-531, 1987.

Körner, C.: Alpine Plant Life: Function Plant Ecology of High Mountain Ecosystems, Springer, Berlin, 1999.

Körner, C. and Paulsen, J.: A world-wide study of high altitude treeline temperatures, J. Biogeogr., 31, 713-732, 2004.

Lan, Y., Ding, Y., Kang, E., and Zhang, J.: The relationship between ENSO cycle and temperature, precipitation and runoff in the Qilian Mountain area, J. Geog. Sci., 13, 293-298, 2003.

Li, J., Xie, S. P., Cook, E. R., Huang, G., D’Arrigo, R., Liu, F., Ma, J., and Zheng, X.-T.: Interdecadal modulation of El Niño amplitude during the past millennium, Nat. Clim. Change, 1, 114-118, 2011.

Li, Z., Zhang, Q., and Ma, K.: Tree-ring reconstruction of summer temperature for A.D. 1475-2003 in the central Hengduan Mountains, Northwestern Yunnan, China, Clim. Change., 110, 455467, doi:10.1007/s10584-011-0111-z, 2011a.

Li, Z., Shi, C. M., Liu, Y., Zhang, J., Zhang, Q., and Ma, K.: Summer mean temperature variation from 1710-2005 inferred from tree-ring data of the Baimang Snow Mountains, northwestern Yunnan, China, Clim. Res., 47, 207-218, 2011 b.

Liang, E. Y., Shao, X. M., and Xu, Y.: Tree-ring evidence of recent abnormal warming on the southeast Tibetan Plateau, Theor. Appl. Climatol., 98, 9-18, doi:10.1007/s00704-008-00856, 2009.

Liang, E. Y., Shao, X. M., Eckstein, D., Huang, L., and Liu, X. H.: Topography- and species-dependent growth responses of Sabina przewalskii and Picea crassifolia to climate on the northeast Tibetan Plateau, Forest. Ecol. Manag., 236, 268-277, 2006.

Liang, E. Y., Wang, Y. F., Xu, Y., Liu, B. M., and Shao, X.: Growth variation in Abies georgei var. smithii along altitudinal gradients in the Sygera Mountains, southeastern Tibetan Plateau, Trees, 24, 363-373, 2010.

Liang, E. Y., Shao, X. M., and Qin, N. S.: Tree-ring based summer temperature reconstruction for the source region of the Yangtze River on the Tibetan Plateau, Global. Planet. Chang., 61, 313320, 2008.

Liu, J., Yang, B., and Qin, C.: Tree-ring based annual precipitation reconstruction since AD 1480 in south central Tibet, Quat. Int., 236, 75-81, 2011.

Liu, X. and Chen, B.: Climatic warming in the Tibetan Plateau during recent decades, Int. J. Climat., 20, 1729-1742, 2000.

Liu, X. H., Shao, X. M., Zhao, L. J., Qin, D. H., Chen, T., and Ren, J. W.: Dendroclimatic temperature record derived from treering width and stable carbon isotope chronologies in the middle Qilian Mountains, China, Arct. Antarct. Alp. Res., 39, 651-657, 2007.

Liu, Y., An, Z., Linderholm, H. W., Chen, D., Song, H., Cai, Q., Sun, J., and Tian, H.: Annual temperatures during the last 2485 years in the Eastern Tibetan Plateau inferred from tree rings, Sci. China. Ser. D., 52, 348-359, 2009.

Lv, L.-X. and Zhang, Q.-B.: Tree-ring based summer minimum temperature reconstruction for the southern edge of the QinghaiTibetan Plateau, China, Clim. Res., 56, 91-101, 2013. 
MacDonald, G. M. and Case, R. A.: Variations in the Pacific Decadal Oscillation over the past millennium, Geophys. Res. Lett., 32, L08703, doi:10.1029/2005GL022478, 2005.

Manabe, S. and Broccoli, A.: Mountains and arid climate of middle latitudes, Science, 247, 192-195, 1990.

Mann, M. E., Bradley, R. S., and Hughes, M. K.: Northern hemisphere temperatures during the past millennium: inferences, uncertainties and limitations, Geophys. Res. Lett., 26, 759-762, 1999.

Mann, M. E., Cane, M. A., Zebiak, S. E., and Clement, A.: Volcanic and solar forcing of the Tropical Pacific over the past 1000 years, J. Clim., 18, 447-456, 2005.

Mantua, N. J., Hare, S. R., Zhang, Y., Wallace, J. M., and Francis, R. C.: A Pacific interdecadal oscillation with impacts on salmon production, Bull. Amer. Meteor. Soc., 78, 1069-1079, 1997.

Mayr, S.: Limits in water relations, in: edited by: Wieser, G. and Tausz, M., Trees at their Upper limits, Springer, Dordrecht, 145162, 2007.

Meko, D. M., Touchan, R., and Anchukaitis, K. J.: Seascorr: A MATLAB program for identifying the seasonal climate signal in an annual tree-ring time series, Comput. Geosci., 37, 1234-1241, doi:10.1016/j.cageo.2011.01.013, 2011.

Michaelsen, J.: Cross-validation in statistical climate forecast models, J. Climate Appl. Meteorol., 26, 1589-1600, 1987.

Minobe, S.: A 50-70 year climatic oscillation over the North Pacific and North America. Geophys. Res. Lett., 24, 683-686, 1997.

Mitchell, T. D. and Jones, P. D.: An improved method of constructing a database of monthly climate observations and associated high-resolution grids. Int. J. Climatol., 25, 693-712, 2005.

Moberg, A., Sonechkin, D. M., Holmgren, K., Datsenko, N. M., and Karlen, W.: Highly variable Northern Hemisphere temperatures reconstructed from low- and high resolution proxy data, Nature, 433, 613-617, 2005.

Osborn, T. J., Briffa, K. R., and Jones, P. D.: Adjusting variance for sample size in tree-ring chronologies and other regional mean time series, Dendrochronologia, 15, 89-99, 1997.

Pederson, N., Cook, E. R., Jacoby, G. C., Peteet, D. M., and Griffin, K. L.: The influence of winter temperatures on the annual radial growth of six northern range margin tree species, Dendrochronologia, 22, 7-29, 2004.

Raspopov, O. M., Dergachev, V. A., Esper, J., Kozyreva, O. V., Frank, D., Ogurtsov, M., Kolström, T., and Shao, X.: The influence of the de Vries ( 200-year) solar cycle on climate variations: Results from the Central Asian Mountains and their global link, Palaeogeogr. Palaeocl., 259, 6-16, 2008.

Ren, Z., Xiong, A., and Zou, F.: The quality control of surface monthly climate data in China, J. Appl. Meteorol. Sci., 18, 516523, 2007 (in Chinese).

Ren, Z., Yu, Y., Zou, F., and Xu, Y.: Quality detection of surface historical basic meteorological data, J. Appl. Meteor Sci, 23, 739747, 2012 (in Chinese).

Robock, A. and Mao, J.: The volcanic signal in surface temperature observations, J. Climat., 8, 1086-1103, 1995.

Rossi, S., Deslauriers, A., Gricar, J., Seo, J. W., Rathgeber, C. B. K., Anfodillo, T., Morin, H., Levanic, T., Oven, P., and Jalkanen, R.: Critical temperatures for xylogenesis in conifers of cold climates, Global. Ecol. Biogeogr., 17, 696-707, 2008.
Salzer, M. W. and Hughes, M. K.: Bristlecone pine tree rings and volcanic eruptions over the last $5000 \mathrm{yr}$, Quat. Res., 67, 57-68, 2007.

Salzer, M. W., Hughes, M. K., Bunn, A. G., and Kipfmueller, K. F.: Recent unprecedented tree-ring growth in bristlecone pine at the highest elevations and possible causes, P. Natl. Acad. Sci., 106, 20348-20353, 2009.

Shao, X. M. and Fan, J. M.: Past climate on west Sichuan Plateau as reconstructed from ring-widths of dragon spruce, Quat. Sci., 1, 81-89, 1999. (in Chinese)

Shao, X. M., Xu, Y., Yin, Z.-Y., Zhu, H., and Wang, S.: Climatic implications of a 3585-year tree-ring width chronology from the northeastern Qinghai-Tibetan Plateau, Quat. Sci. Rev., 29, 2111 2122, doi:10.1016/j.quascirev.2010.05.005, 2010.

Shao, X. M., Huang, L., Liu, H. B., Liang, E. Y., Fang, X. Q., and Wang, L. L.: Reconstruction of precipitation variation from tree rings in recent 1000 years in Delingha, Qinghai, Sci. China Ser. D, 48, 939-949, 2005.

Shi, J., Cook, E. R., Lu, H., Li, J., Wright, W. E., and Li, S.: Tree-ring based winter temperature reconstruction for the lower reaches of the Yangtze River in southeast China, Clim. Res., 41, 169-175, 2010.

Shindell, D., Schmidt, G., Mann, M., Rind, D., and Waple, A.: Solar forcing of regional climate change during the Maunder Minimum, Science, 294, 2149-2152, 2001.

Song, H., Liu, Y., Li, Q., Ma, Y., and Zhang, Y.: Tree-ring based May-July temperature reconstruction since AD 1630 on the Western Loess Plateau, China, PLoS ONE, 9, e93504, doi:10.1371/journal.pone.0093504, 2014.

Stokes, M. A. and Smiley, T. L.: An introduction to tree ring dating, The University of Chicago Press, Chicago, 1968.

Stuiver, M. and Braziunas, T. F.: Atmospheric 14C and centuryscale solar oscillations, Nature, 338, 405-408, 1989.

Sun, J. and Liu, Y.: Tree ring based precipitation reconstruction in the south slope of the middle Qilian Mountains northeastern Tibetan Plateau, over the last millennium. J. Geophys. Res., 117, D08108, 2012.

Tan, M., Liu, T. S., Hou, J., Qin, X., Zhang, H., and Li, T.: Cyclic rapid warming on centennial-scale revealed by a 2650 -year stalagmite record of warm season temperature, Geophys. Res. Lett., 30, 1617, doi:10.1029/2003GL017352, 2003.

Thompson, L. G., Mosley-Thompson, E., Davis, M. E., Lin P. N., Henderson, K., and Mashiotta, T. A.: Tropical glacier and ice core evidence of climate change on annual to millennial time scales, Clim. Change, 59, 137-155, 2003.

Tian, Q., Gou, X., Zhang, Y., Wang, Y., and Fan, Z.: May-June mean temperature reconstruction over the past 300 years based on tree rings in the Qilian Mountains of the Northeastern Tibetan Plateau, IAWA J., 30, 421-434, 2009.

Torrence, C. and Compo, G. C.: A practical guide to wavelet analysis, Bull. Amer. Meteor. Soc., 79, 61-78, 1998.

Tranquillini, W.: Physiological ecology of the alpine treeline, Springer, Berlin, 1979

Wang, X. C., Zhang, Q. B., Ma, K. P., and Xiao, S. C.: A treering record of 500-year dry-wet changes in northern Tibet, China, Holocene, 18, 579-588, 2008.

Warren, W. G.: On removing the growth trend from dendrochronological data, Tree-Ring Bull., 40, 35-44, 1980. 
Webster, P. J., Magaña, V. O., Palmer, T. N., Shukla, J., Tomas, P. A., Yanai, M., and Yasunari, T.: Monsoons: processes, predictability, and the prospects for prediction, J. Geophys. Res., 103, 1445114510, 1998.

Wigley, T. M. L., Briffa, K. R., and Jones, P. D.: On the average value of correlated time series, with applications in dendroclimatology and hydrometeorology, J. Clim. Appl. Meteorol., 23, 201-213, 1984.

Xu, W. X. and Liu, X. D.: Response of vegetation in the QinghaiTibet Plateau to global warming, Chinese Geogr. Sci., 17, 151159, 2007.

Yadav, R. R., Braeuning, A., and Singh, J.: Tree ring inferred summer temperature variations over the last millennium in western Himalaya, India, Clim. Dynam., 36, 1545-1554, 2011.

Yadav, R. R., Park, W. K., Singh, J., and Dubey, B.: Do the western Himalayas defy global warming?, Geophys. Res. Lett., 31, L17201, doi:10.1029/2004GL020201, 2004.

Yang, B., Bräuning, A., Johnson, K. R., and Shi, Y. F.: General characteristics of temperature variation in China during the last two millennia, Geophy. Res. Lett., 29, 381-384, 2002

Yang, B., Bräuning, A., Liu, J. J., Davis, M. E., and Shao, Y. J.: Temperature changes on the Tibetan Plateau during the past 600 years inferred from ice cores and tree rings, Global. Planet. Chang., 69, 71-78, 2009b.

Yang, B., Kang, X. C., Brauning, A., Liu, J., Qin, C., and Liu, J. J.: A 622-year regional temperature history of southeast Tibet derived from tree rings, Holocene, 20, 181-190, 2010.

Yang, B., Kang, X., Liu, J., Bräuning, A., and Qin, C.: Annual temperature history in Southwest Tibet during the last 400 years recorded by tree rings, Int. J. Climatol., doi:10.1002/joc.1956, 2009a.

Yang, B., Qin, C., Bräuning, A., Burchardt, I., and Liu, J.: Rainfall history for the Hexi Corridor in the arid northwest China during the past 620 years derived from tree rings, Int. J. Climatol., 31, 1166-1176, 2011.

Yang, B., Qin, C., Wang, J., He, M., Melvin, T. M., Osborn, T. J., and Briffa, K. R.: A 3,500-year tree-ring record of annual precipitation on the northeastern Tibetan Plateau, P. Natl. Acad. Sci., 111, 2903-2908, 2014.

Yang, L. and Zhao, J.-B.: Effect of ENSO events on climate and climate disasters in the Hexi Corridor, Gansu Province, Arid Zone Res., 29, 949-955, 2012. (In Chinese)

Yang, Q., Liu, J., and Wang, Y.: Survey report in the National Nature Reserve of Qilian Mountains, Gansu, Gansu Science \& Technology Press, Lanzhou, 2008 (in Chinese).
Yao, T., Wang, Y., Liu, S., Pu, J., Shen, Y., and Lu, A.: Recent glacial retreat in High Asia in China and its impact on water resource in Northwest China, Sci. China. Ser. D., 47, 1065-1075, 2004.

Yao, T., Thompson, L., Yang, W., Yu, W., Gao, Y., Guo, X., Yang, X., Duan, K., Zhao, H., Xu, B., Pu, J., Lu, A., Xiang, Y., Kattel, D. B., and Joswiak, D.: Different glacier status with atmospheric circulations in Tibetan Plateau and surroundings, Nat. Clim. Change, 2, 663-667, doi:10.1038/NCLIMATE1580, 2012.

Zhang, C., Zhao, J., Luo, X., and Chen, L.: Correlation between ENSO events and climate impacts in Gansu for 60 years, J. Arid Land Resour. Environ., 25, 106-113, 2011 (in Chinese).

Zhang, T., Yuan, Y., Wei, W., Yu, S., Zhang, R., Chen, F., Shang, H., and Qin, L.: A tree-ring based precipitation reconstruction for the Mohe region in the northern Greater Higgnan Mountains, China, since AD 1724, Quat. Res., 82, 14-21, doi:10.1016/j.yqres.2014.01.007, 2014.

Zhang, T., Yuan, Y., Liu, Y., Wei, W., Zhang, R., Chen, F., Yu, S., Shang, H., and Qin, L.: A tree-ring based temperature reconstruction for the Kaiduhe River watershed, northwestern China, since A.D. 1680: Linkages to the North Atlantic Oscillation, Quat. Int., 311, 71-80, 2013.

Zhang, Y., Tian, Q., Gou, X., Chen, F., Leavitt, S. W., and Wang, Y.: Annual precipitation reconstruction since AD 775 based on tree rings from the Qilian Mountains, northwestern China, Int. J. Climatol., 31, 371-381, 2011.

Zhou, X. J., Zhao, P., Chen, J. M., Chen, L. X., and Li, W. L.: Impacts of thermodynamic processes over the Tibetan Plateau on the Northern Hemispheric climate, Sci. China. Ser. D., 52, 16791693, 2009.

Zhu, H. F., Shao, X. M., Yin, Z. Y., and Huang, L.: Early summer temperature reconstruction in the eastern Tibetan plateau since AD 1440 using tree-ring width of Sabina tibetica, Theor. Appl. Climatol., 106, 45-53, 2011a.

Zhu, H. F., Shao, X. M., Yin, Z. Y., Xu, P., Xu, Y., Tian, H.: August temperature variability in the southeastern Tibetan Plateau since AD 1385 inferred from tree rings, Palaeogeogr. Palaeocl., 305, 84-92, 2011b.

Zhu, H. F., Zheng, Y. H., Shao, X. M., Liu, X. H., Xu, Y., and Liang, E. Y.: Millennial temperature reconstruction based on tree-ring widths of Qilian juniper from Wulan, Qinghai Province, China, Chinese Sci. Bull., 53, 3914-3920, doi:10.1007/s11434008-0400-8, 2008. 